\title{
Impaired glycocalyx barrier properties contribute to enhanced intimal low-density lipoprotein accumulation at the carotid artery bifurcation in mice
}

\author{
Bernard M. van den Berg • Jos A. E. Spaan • Hans Vink
}

Received: 3 June 2008 / Accepted: 17 September 2008/Published online: 7 October 2008

(C) The Author(s) 2008. This article is published with open access at Springerlink.com

\begin{abstract}
The glycocalyx contributes to the barrier properties of vascular endothelium, and recently, we reported using electron microscopy that glycocalyx is diminished at lesion prone sites in arterial bifurcations in mice. In the present study, we examined using confocal microscopy the dimension and composition of the endothelial glycocalyx at low- and high-risk atherogenic regions within the common carotid (common) and internal carotid branch (sinus) of C57BL/6J mice and compared dimensional variations with its ability to limit transendothelial leakage of low-density lipoprotein (LDL). Confocal laser scanning microscopy of arterial surfaces stained for heparan sulfate and hyaluronan revealed thinner glycocalyces at the sinus region $(2.2 \pm 0.7$ and $2.3 \pm 0.7 \mu \mathrm{m}$, respectively; $P<0.05$ ) than the glycocalyx thickness at the common region $(4.3 \pm 1.6$ and $4.3 \pm 1.6 \mu \mathrm{m}$, respectively). This thinner glycocalyx was associated with impaired LDL retention by the glycocalyx resulting in a two to three times increase in intimal accumulation of LDL $15 \mathrm{~min}$ after i.v. bolus administration: $10.8 \pm 5.6$ vs. $4.0 \pm$ $1.9 \times 10,000$ a.u. (sinus vs. common, $P<0.05$ ). These results
\end{abstract}

B. M. van den Berg $\cdot H$. Vink $(\varangle)$

Department of Physiology, CARIM, Maastricht University,

Universiteitssingel 50, 6229 ER, P.O. Box 616, 6200 MD

Maastricht, The Netherlands

e-mail: h.vink@fys.unimaas.nl

H. Vink

Department of Vascular Medicine, Academic Medical Center,

University of Amsterdam,

Amsterdam, The Netherlands

J. A. E. Spaan

Department of Medical Physics, Academic Medical Center,

University of Amsterdam,

Amsterdam, The Netherlands indicate that impaired glycocalyx barrier properties may contribute to transendothelial leakage of atherogenic LDL at lesion prone arterial sites.

Keywords Carotid artery bifurcation - Glycocalyx $\cdot$ Heparan sulfate $\cdot$ Hyaluronan $\cdot$ Permeability

\section{Introduction}

The endothelial surface glycocalyx contributes to the vascular barrier function in shielding the vascular wall from flowing blood and limiting leakage of fluid and macromolecules across its endothelial lining. Recently, we demonstrated using electron microscopy that the morphology and dimension of the endothelial glycocalyx was dramatically modified at atherogenic risk areas or by a high-fat diet, and such glycocalyx perturbation was accompanied by a local increased intima-to-media ratio [29]. In this paper, we extend this line of research and focus on structural glycocalyx differences at arterial lesion-prone sites and its consequences for local permeability barrier properties with respect to transendothelial leakage of the atherogenic risk factor low-density lipoprotein (LDL).

Numerous studies that contributed to eluding the endothelial glycocalyx composition [24, 25] resulted in the view of a negatively charged mesh of proteoglycans, glycosaminoglycans (GAG), glycoproteins, and glycolipids on the luminal surface of vascular endothelial cells extending well into the lumen of blood vessels. In particular, heparan sulfate (HS) and hyaluronan (HA) have been found to be intimately involved in vascular homeostasis $[12,14,30]$ and regulating the release of nitric oxide (NO) by serving as a mechano-shear sensor for NO release $[7,20,22,35]$. 
The extended endothelial glycocalyx is believed to appear as a mesh of soluble proteoglycan core proteins bearing HS and chondroitin sulfate side chains linked to each other or to plasma proteins and HA, the only GAG not covalently linked to a peptide core [25]. As a result of the dynamic equilibrium between biosynthesis and shedding of the various components, a geometrical definition of the glycocalyx is still elusive $[10,21]$. In addition, our observations that perturbation of the endothelial glycocalyx by atherogenic stimuli, such as oxidative stress [33] and oxidized-LDL $[3,4,34]$, increase vascular permeability and adhesiveness of platelets and leukocytes to the cell surface exemplifies the importance of considering the synergistic interaction of the glycocalyx constituents as a whole.

In the present study, we investigated the role of HS and HA at low- and high-risk atherogenic regions of the mouse carotid artery, using the common and internal carotid sinus area as a model for arterial sites exposed to low- or highatherogenic risk, respectively [17]. We hypothesized that a diminished glycocalyx at atherogenic risk areas is characterized with reduced amounts of both HS and HA that contributes to local impairment of barrier properties and, in turn, increased permeability for high molecular weight plasma molecules.

Confocal laser scanning microscopy (CLSM) was performed to study the endothelial HS and HA thickness and surface distribution on freshly isolated carotid artery bifurcation segments of $\mathrm{C} 57 \mathrm{BL} / 6 \mathrm{~J}$ (B6) mice, incubated with anti-HS antibody [5] and purified HA-binding protein (HABP). To test for increased local vascular permeability $[2,8,27]$, leakage of the fluorescent LDL-Bodipy $\mathrm{FL}$ complex (LDL-bodipy) at the carotid artery low- and highrisk regions was investigated. Furthermore, the effect of HS and HA surface distribution was evaluated at low- and high-risk regions of the carotid artery bifurcation segment to a systemic atherogenic challenge, in $\mathrm{C} 57 \mathrm{BL} / 6 \mathrm{~J} / \mathrm{apoE} * 3$ Leiden $(E 3 L)$ mice on a Western-type diet containing $0.25 \%$ cholesterol [32] or glycocalyx degradation with hyaluronidase of $B 6$ vessel segments.

\section{Materials and methods}

Mice Fifteen-week-old male C57BL/6J (B6) mice were divided into two groups: non-challenged controls (weight, $27.0 \pm 1.0 \mathrm{~g}, n=6)$ and intravenously challenged with fluorescent human plasma LDL analogue (LDL-bodipy, Molecular Probes, Eugene, OR, USA; weight, $26.9 \pm 1.1 \mathrm{~g}$, $n=6$ ). In addition, one group of 18-week-old male C57BL/ $6 \mathrm{~J} /$ apoE*3-Leiden $(E 3 L)$ mice (weight $29.2 \pm 1.7 \mathrm{~g}, n=4)$ on standard mouse chow (SRM-A; Hope Farms, Woerden, The Netherlands) were put on a high-fat, high-cholesterol diet containing $15 \%$ cacao butter, $0.25 \%$ cholesterol, $40.5 \%$ sucrose, $10 \%$ corn starch, $1 \%$ corn oil, and $5.95 \%$ cellulose (Diet-W; Hope Farms) for 4 weeks, as described earlier [29]. The experimental protocol was approved by the local Animal Ethical Committee of the Academic Medical Center and University of Amsterdam.

Changes in cholesterol and triglyceride serum levels of $E 3 L$ mice between weeks 18 (pre-diet) and 22 (4 weeks on diet) were determined from blood collected by saphenous vein puncture [13], using the MPR2 cholesterol kit (Boehringer Mannheim, Germany) and GPO-Trinder kit (Sigma-Aldrich, St. Louis, MO, USA), respectively.

In vivo LDL-bodipy challenge Mice received an intraperitoneal dose of 25 IU heparin (Leo Pharma BV, Weesp, The Netherlands). After $15 \mathrm{~min}$, it was followed by an intraperitoneal dose of $125 \mathrm{mg} / \mathrm{kg}$ ketamine $\mathrm{HCl}$ (Eurovet, Bladel, The Netherlands) and $0.2 \mathrm{mg} / \mathrm{kg}$ medetomidine $\mathrm{HCl}$ (Orion, Expoo, Finland). The left external jugular vein was exposed and cannulated to administrate $60 \mu \mathrm{g}$ of LDLbodipy, which was allowed to circulate for $15 \mathrm{~min}$ before dissection of the left common carotid artery and bifurcation area. This amount of LDL-bodipy was estimated to correspond with approximately $0.2 \mathrm{mmol} / \mathrm{L}$ of circulating LDL, about twice the plasma LDL content in $B 6$ mice [15]. LDL-bodipy that was prepared from fresh human plasma and stored under argon by the manufacturer was used within 2 days upon arrival.

Tissue preparation and CLSM Mice received an intraperitoneal dose of 25 IU heparin, followed after 15 minutes by an intraperitoneal dose of $125 \mathrm{mg} / \mathrm{kg}$ ketamine $\mathrm{HCl}$ and $0.2 \mathrm{mg} / \mathrm{kg}$ medetomidine $\mathrm{HCl}$, as shown above. The left common carotid artery and bifurcation area were exposed, and the common carotid artery was ligated proximal to the aortic arch bifurcation. The left common carotid artery plus internal and external carotid arteries were dissected as a whole and placed in oxygenated 4-2-hydroxyethyl-1-piperazineethanesulfonic acid (HEPES)-buffered salt solution (HBSS, in mmol/L: 5.55 glucose, $114 \mathrm{NaCl}, 10 \mathrm{KCl}, 1.18$ $\mathrm{KH}_{2} \mathrm{PO}_{4}, 1.17 \mathrm{MgSO}_{4} \cdot 7 \mathrm{H}_{2} \mathrm{O}, 0.5 \mathrm{CaCl}_{2}, 25 \mathrm{NaHCO}_{3}, 5.0$ HEPES, 0.025 EDTA; pH $7.41 \pm 0.03$ ) containing $0.1 \%$ bovine serum albumin at room temperature (rT), and the animal is killed. Excess tissue was removed, and the common carotid artery and bifurcation area were cut open longitudinally to expose the endothelial cell (EC) surface and, except of LDL-bodipy challenged mice, incubated with $50 \mu \mathrm{g} / \mathrm{mL}$ of purified HABP (Seikagaku America, Falmouth, MA, USA) conjugated to Alexa Fluor 555 (HABP-AF555; custom synthesis by Molecular Probes), followed by incubation with mouse anti-heparan sulfate IgM antibody $(10 \mu \mathrm{g} / \mathrm{mL}$, clone 10E4; Seikagaku, Tokyo, Japan) and after a brief wash, with Alexa Fluor 488 
conjugated goat anti-mouse $\operatorname{IgM}(10 \mu \mathrm{g} / \mathrm{mL}$, Molecular Probes). All proceedings were performed in HBSS-bovine serum albumin (BSA) for $30 \mathrm{~min}$ at $\mathrm{rT}$. The EC surface of segments placed between two cover slips in the presence of SYTO $44(2 \mu \mathrm{mol} / \mathrm{L}$, Molecular Probes) were examined using a CLSM (510-meta; Carl Zeiss, Göttingen, Germany) and $\mathrm{a} \times 40$ objective lens (Plan Neo Fluar NA 1.3/oil DIC; Carl Zeiss).

In addition, some right whole carotid bifurcation segments of control B6 mice with exposed EC surface, not challenged with LDL-bodipy $(n=4)$, were incubated with $25 \mathrm{IU} / \mathrm{mL}$ hyaluronidase (bovine testis, fraction IV-S) in HBSS-BSA for $1 \mathrm{~h}$ at $37^{\circ} \mathrm{C}$, in the presence of $1 \mathrm{mmol} / \mathrm{L}$ benzamidine- $\mathrm{HCl}$ and $5 \mathrm{mmol} / \mathrm{L}$ 6-amino- $n$-caproic acid (all Sigma Chemical). After a brief wash with HBSS-BSA, the bifurcation segments were incubated with the preceding HA and HS labeling steps and examined as shown above.

Data analysis Confocal 12-bit gray-scale axial image stacks ( $x y z$ dimensions, $0.04 \times 0.04 \times 0.3 \mu \mathrm{m}$ ) starting from the vessel lumen that covered $400 \mu^{2}$ of surface area per image and a height of 5 to $10 \mu \mathrm{m}$ above and below the EC nuclear plane were recorded using LSM-5 Image software (Carl Zeiss). The image stacks were analyzed with the public domain National Institutes of Health IMAGE program (available at http://rsb.info.nih.gov/nih-image). For each image, the mean fluorescence minus background fluorescence (first five luminal images from stack) was determined, and within each stack, the nuclear position of EC and adjacent smooth muscle cell (SMC) was determined from corresponding SYTO 44 peak fluorescence.

Glycocalyx thickness was estimated to be the distance between the HS- or HA-stained luminal boundary focal plane and peak EC nuclear position. Sum of HS and HA glycocalyx staining was determined to be between the respective luminal boundary focal plane and distal EC nucleus half-maximum fluorescence. Spatial localization differences within the glycocalyx domain between HS and HA was evaluated by their respective calculated coefficient of variance. Intimal LDL distribution and HA, HS accessibility for each labeled conjugate (HABP-AF555 and mouse anti-HS/goat anti-mouse IgM-AF488, respectively) were determined to be the sum of fluorescence of each label between EC and adjacent SMC nuclear halfmaximum fluorescent position and were compared with the total sum of fluorescence of intimal and glycocalyx domain.

Data are presented as mean \pm SD. Differences in measurements between common carotid- and internal carotid artery sinus region within each group and in serum cholesterol- and triglyceride levels between pre-diet and diet in $E 3 L$ mice were assessed by means of paired-sample $t$ test (two-way). Differences in measurements between experimental groups were assessed by means of two-sample $t$ test (two-way). A value of $P<0.05$ was considered statistically significant.

\section{Results}

Glycocalyx dimension in B6 mice on normal diet Dimension estimates from axial confocal image stacks revealed significantly $(P<0.05)$ thinner HS and HA domains $(2.2 \pm$ 0.7 and $2.3 \pm 0.7 \mu \mathrm{m}$, respectively) at the left internal carotid sinus region of $B 6$ mice than the glycocalyx thickness of $4.3 \pm 1.6$ and $4.3 \pm 1.6 \mu \mathrm{m}$ found at the common carotid artery surface (Fig. 1a). Local difference in glycocalyx thickness was accompanied by significantly less $(P<0.05)$ fluorescent staining for HA and a disproportionate reduction in HS (Fig. 1b). This was illustrated by the $z$-axis average intensity projections of the common- and internal carotid sinus region (Fig. 2a, b, respectively).

Surface-staining patterns of HS and HA fluorescence were significantly different $(P<0.05$, HS vs. HA), as illustrated by their respective coefficients of variance $(102 \pm 26$ vs. $58 \pm 13$ at common region and $120 \pm 44$ vs. $66 \pm 20$ at sinus region) and en face intensity projections (Fig. 1c-i). Interdependence of HS and HA structures within the glycocalyx domain was noticed further in $B 6$ carotid artery bifurcation segments after hyaluronidase treatment (Fig. 3). In line with the treatment, HA surface amount was reduced significantly $(P<0.05)$ at both the sinus and common region of the carotid artery $(42 \pm$ $16 \%$ and $50 \pm 5 \%$ of total vascular HA staining, respectively) in comparison with sinus and common region surface HA of control $B 6$ mice ( $78 \pm 8 \%$ and $85 \pm 6 \%$, respectively), illustrated by $z$-axis average intensity projections of the common and internal carotid sinus region (Fig. $2 \mathrm{c}$ and d, respectively). Consequently, accessibility for intimal HA staining increased to a sum of fluorescence of $4,948 \pm 2,478$ and $4,306 \pm 2,502$ for sinus and common region in comparison with their respective sinus and common region intimal $\mathrm{HA}$ fluorescence of control B6 mice $(2,564 \pm 1,530$ and $2,853 \pm 1,217$ a.u., respectively). Surprisingly, in conjunction with the expected reduction of HA, hyaluronidase treatment also resulted in a similar reduction of HS at both sinus and common region ( $45 \pm 13 \%$ vs. $80 \pm 9 \%$ and $52 \pm 7 \%$ vs. $86 \pm 9 \%$ of total vascular HS staining, respectively). Accessibility of intimal HS for staining also increased upon hyaluronidase treatment resulting in a sum of fluorescence of 2,073 $\pm 2,214$ and 3,583 $\pm 3,064$ for sinus and common region in comparison with sinus and common region intimal HS fluorescence of control $B 6$ mice (681 \pm 585 and 1,321 $\pm 1,213$ a.u., respectively). Despite the reduction in surface presence of HS and HA upon treatment with hyaluronidase, surface-staining patterns remained very similar as was found in control $B 6$ mice with significantly different patterns of HS and HA fluorescence $(P<0.05$, HS vs. HA), as illustrated by their respective 
Fig. 1 Distribution of HS and HA surface thickness (a) and HS and HA surface coverage (b) at the common carotid- and internal carotid sinus region of $B 6$ mice. Values are means $\pm \mathrm{SD}$ $(n=6)$. Difference in HS and HA thickness or coverage between common and sinus region of the carotid artery was assessed by means of paired-sample $t$ test (two-way). ${ }^{*} P<0.05$ vs. common region. En face averageintensity projections of mouse left common carotid (c-e) and internal carotid sinus (f- $-\mathbf{g})$ glycocalyx domain. Projections are from axial image stacks starting from HS (green, $\mathbf{c}$ and f) or HA (red, $\mathbf{d}$ and $\mathbf{g}$ ) luminal boundary focal-plane up to the respective endothelial nucleus half maximum fluorescence (blue). Third column (e and $\mathbf{h})$ are merged images of first and second image column. Each image covers a surface area of $400 \mu \mathrm{m}^{2}$, bar $=5.0 \mu \mathrm{m}$
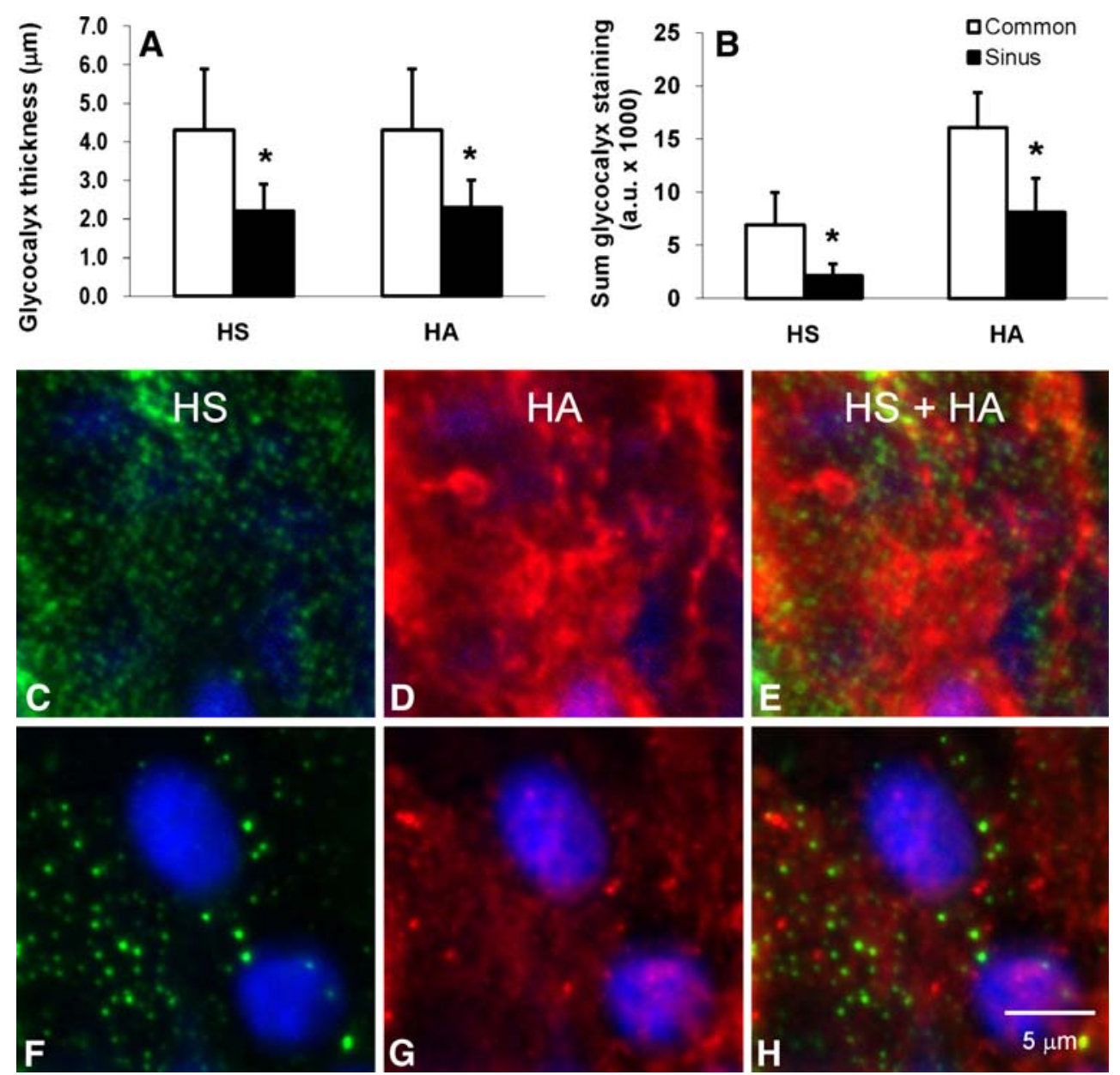

B6

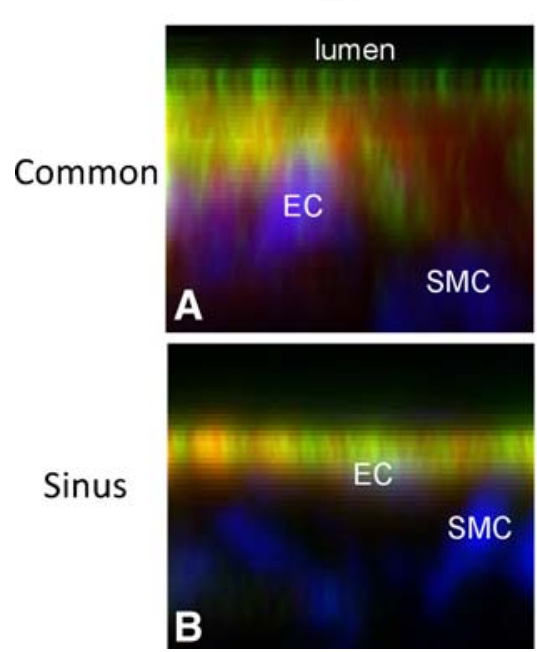

$B 6+$ hyaluronidase
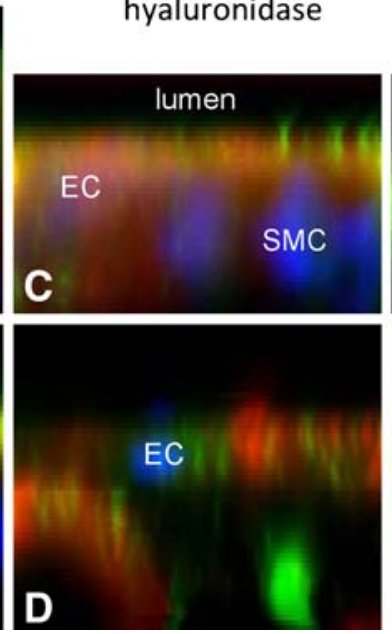

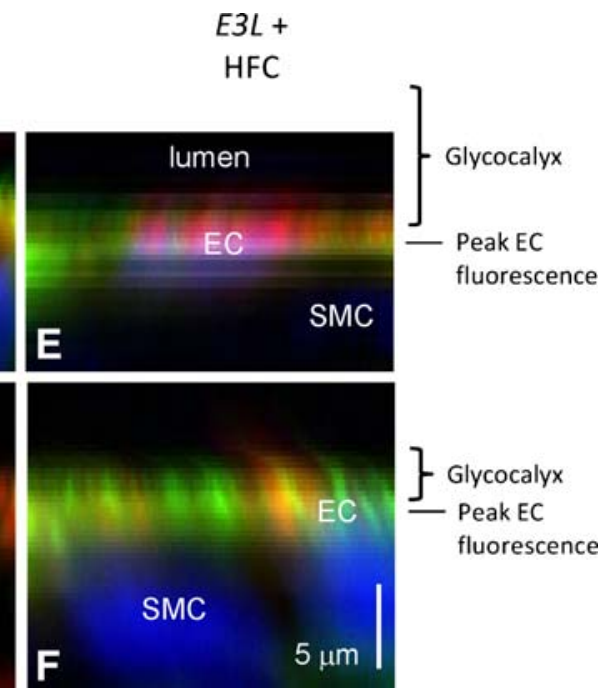

Fig. $2 Z$-axis average-intensity projections of HS and HA distribution at the common carotid and internal carotid sinus region of $B 6$ (a and b, respectively) mice on standard diet, murine $B 6$ vessel segments treated with hyaluronidase (c and $\mathbf{d}$, respectively) and of E3L mice on a high-fat, high-cholesterol diet for 4 weeks(e and $\mathbf{f}$, respectively). Projections are from axial image stacks starting in the vascular lumen (lumen) into the vascular wall. Combined HS- (green) and HA-stained (red) luminal glycocalyx domain (Glycocalyx) and intimal vascular wall are projected. Black line and EC represents the endothelial nucleus position at peak fluorescence (blue), SMC represents smooth muscle cell nucleus (blue). Bar $=5.0 \mu \mathrm{m}$ 


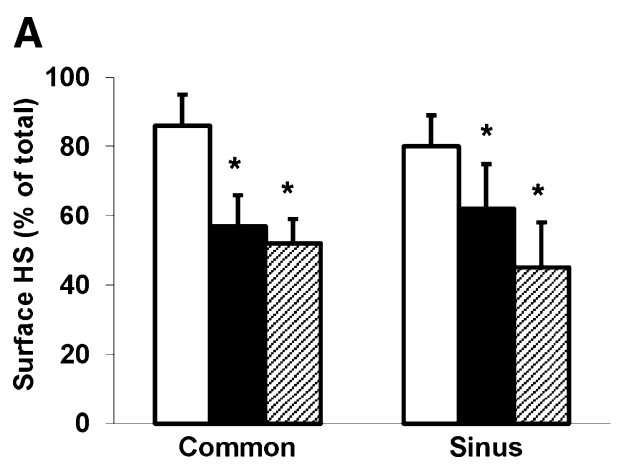

Fig. 3 Comparison of HS (a) and HA (b) surface distribution at common carotid- and internal carotid sinus region between control $B 6$ mice, $E 3 L$ mice on high-fat, high-cholesterol diet $(H F C)$ for 4 weeks $(n=4)$ and $B 6$ carotid artery segment treated with $25 \mathrm{IU} / \mathrm{mL}$ hyaluronidase (hyal) for $1 \mathrm{~h}$ at $37^{\circ} \mathrm{C}(n=4)$. Values are means \pm SD.

coefficients of variance $(106 \pm 23$ vs. $66 \pm 15$ at common region and $111 \pm 27$ vs. $73 \pm 18$ at sinus region).

Vascular LDL-bodipy distribution in B6 mice on normal diet To investigate whether quantitative differences in glycocalyx constituents would affect local vascular wall-barrier properties, $B 6$ mice were intravenously challenged with LDLbodipy for about $15 \mathrm{~min}$ before dissection of the carotid artery bifurcation segment. Visualization of the dissected vessel

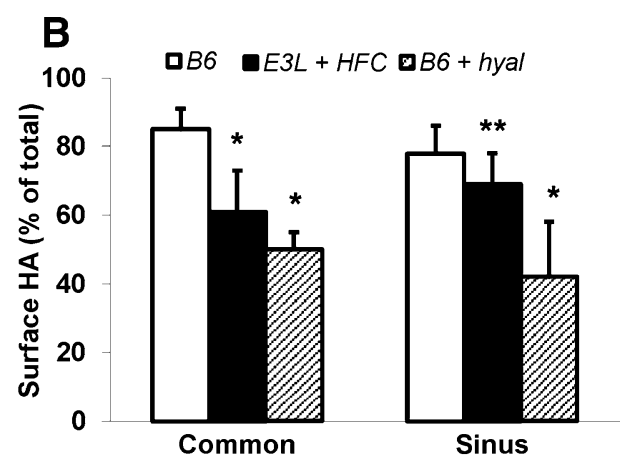

Difference in HS and HA surface distribution between control B6 mice and each challenge and between challenged groups was assessed by means of two-sample $t$ test (two-way). ${ }^{*} P<0.05$ vs. control $B 6$. $* * P<0.05$ vs. $B 6$ treated with hyaluronidase

segments revealed a marked distribution difference of the fluorescent LDL analogue between the common (Fig. 4a) and sinus region (Fig. 4b). LDL-bodipy leaking into the intimal layer was significantly $(P<0.05)$ higher at the sinus than at the common region $(10.8 \pm 5.6$ vs. $4.0 \pm 1.9 \times 10,000$ a.u., respectively; Fig. 4c). Within the sinus region, an intracellular endothelial LDL-bodipy accumulation was found, contained within vesicle-like structures, that was absent in the common region EC domain cytoplasm (Fig. 4d,e).
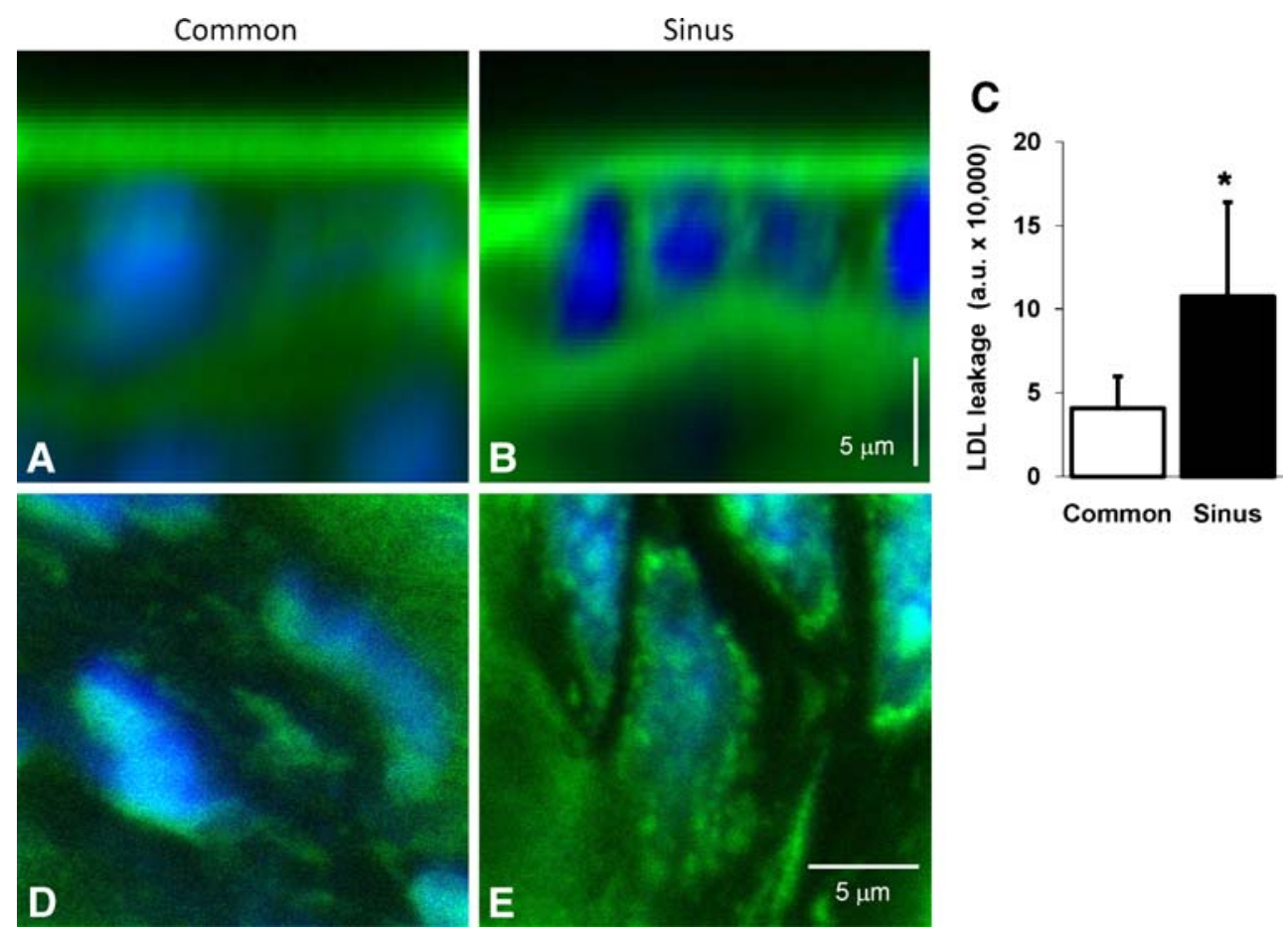

Fig. $4 Z$-axis average-intensity projections of the fluorescent LDL analogue LDL-bodipy (green) distribution through the vascular wall of common carotid (a) and internal carotid sinus artery region (b) of control B6 mice. Sub-endothelial accumulation of LDL-bodipy in common carotid and internal carotid sinus vascular wall of $B 6$ mice $(n=6)$ after in vivo LDL-bodipy challenge $(\mathbf{c})$. Values are means \pm SD.
Difference in sub-endothelial LDL-bodipy accumulation between the common and internal carotid region was assessed by means of pairedsample $t$ test (two-way). $* P<0.05$ vs. common region. En face averageintensity projections of intracellular LDL-bodipy (green) distribution at the endothelial nuclear (blue) plane of mouse left common carotid (d) and internal carotid sinus artery region (e). Bar $=5.0 \mu \mathrm{m}$ 


\section{Glycocalyx distribution in E3L mice on atherogenic diet}

Comparison of HS and HA distribution within the carotid artery of $B 6$ mice on a normal diet revealed similar differences in surface coverage between the "atheroprotective" common region and the "atheroprone" internal sinus region with a significant thinner glycocalyx at the latter site. While surface distribution of HS and HA at each site was very different, interdependence between the two glycocalyx constituents was observed upon enzymatic treatment of the vessel segment with hyaluronidase. To assess the effect of in vivo cardiovascular risk factors on the endothelial glycocalyx, E3L mice were put on a Western-type, high-fat highcholesterol diet for 4 weeks to induce the onset of systemic dislipidemia a risk factor for atherosclerotic lesion formation. In this relatively short period of atherogenic diet, $E 3 L$ mice started to have significant higher serum levels of cholesterol $(7.1 \pm 2.2$ vs. $3.0 \pm 1.0 \mathrm{mmol} / \mathrm{L}, P<0.05)$ and increased levels of triglycerides $(1.4 \pm 0.4$ vs. $0.9 \pm 0.6 \mathrm{mmol} / \mathrm{L}, P=0.192)$ than before they started the diet (Table 1 ). This early modest dislipidemia was associated with reduced amounts of surface HS and HA at both common carotid artery surface (57 $\pm 9 \%$ and $61 \pm 12 \%$ of total vascular staining for HS and HA, respectively) and sinus region (62 $13 \%$ and $69 \pm 9 \%)$ in comparison to the presence of surface HS and HA in control $B 6$ mice (common $86 \pm 9 \%$ and $85 \pm 6 \%$; sinus $80 \pm 9$ and $78 \pm$ 8), Fig. 3, and illustrated in Fig. 2e and f, respectively. Accessibility of intimal HS and HA for staining also increased in these $E 3 L$ mice on atherogenic diet and resulted in a sum of fluorescence of 1,615 $\pm 1,080$ and 2,806 $\pm 1,566$ for labeled HS in sinus and common region, respectively,

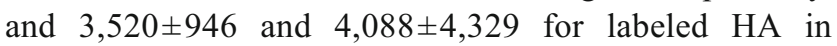
comparison to intimal HS and HA fluorescence in sinus and common region of control B6 mice (HS $681 \pm 585$ and $1,321 \pm 1,213$ a.u.; HA $2,564 \pm 1,530$ and $2,853 \pm 1,217$ a.u.). This diet-induced reduction in surface HS and HA presence, however, resulted in changes of especially a HS surfacestaining pattern, rendering it indistinguishable from the HA surface-staining pattern, as illustrated by their respective

Table 1 Serum cholesterol and triglyceride levels in E3L mice on high-fat, high-cholesterol diet (containing 15\% cacao butter and $0.25 \%$ cholesterol) for 4 weeks

\begin{tabular}{lllc}
\hline & Weight $(\mathrm{g})$ & $\begin{array}{l}\text { Cholesterol } \\
(\mathrm{mmol} / \mathrm{L})\end{array}$ & $\begin{array}{l}\text { Triglycerides } \\
(\mathrm{mmol} / \mathrm{L})\end{array}$ \\
\hline Pre-diet & $24.7(3.8)$ & $3.0(1.0)$ & $0.9(0.6)$ \\
4 weeks on diet & $29.2(1.7)^{*}$ & $7.1(2.2)^{*}$ & $1.4(0.4)$ \\
\hline
\end{tabular}

The difference in body weight, serum cholesterol, and triglyceride levels before and after 4 weeks of diet in E3L mice $(n=4)$ was assessed by means of paired-sample $t$ test (two-way). Results are means \pm SD. $* P<0.05$, pre-diet vs. post diet coefficients of variance ( $55 \pm 32$ vs. $60 \pm 16$ at common region and $89 \pm 21$ vs. $46 \pm 24$ at sinus region). This change in HS surface distribution might be primarily as a result of its involvement in vascular lipid accumulation, via bound lipoprotein lipase [26].

\section{Discussion}

In line with our earlier electron microscopic observations [29], we found significant smaller glycocalyx dimensions and amounts for two of its major constituents heparan sulfate and hyaluronan at the atherogenic sinus region of the carotid artery bifurcation compared with the common carotid region. This locally reduced glycocalyx was associated with increased sub-endothelial accumulation of LDL, supporting the hypothesis that perturbed glycocalyx content at pre-lesion areas within the arterial vascular tree contributes to local loss of EC barrier properties. Hyaluronidase treatment of $B 6$ carotid artery bifurcation vessel segment not only affected the amount of surface HA but reduced HS surface coverage equally, demonstrating the interdependence of intermingled GAGs. Furthermore, despite globally reduced surface HS and HA amounts in an atherogenic mouse model put on a high-fat, high-cholesterol diet, preexisting local relative differences in glycocalyx dimensions remained unaltered, indicating that increased atherogenic vulnerability remains localized at spatially defined vascular regions.

Using various fluorescent-microscopic approaches, EC surface dimensions were reported from $0.5 \mu \mathrm{m}$ within capillaries and small arterioles [4, 14, 33, 34], $2.6 \mu \mathrm{m}$ in small diameter arteries [31], up to about $4.5 \mu \mathrm{m}$ lining the common carotid artery [19]. Consistent with the latter twophoton laser scanning microscopic measurements of lectinstained murine common carotid surface layer, we now report 4.3- $\mu \mathrm{m}$ thick HS and HA glycocalyx dimensions at the common carotid artery region of $B 6$ mice. In addition, we were able to measure distinct local glycocalyx dimensions within the common and sinus region of the carotid bifurcation and associated differences in local GAG amounts, which extend our previous electron microscopic reports of distributed glycocalyx dimensions [29, 30]. From these studies, a possible role of the endothelial glycocalyx in control of vascular wall permeability emerged, as suggested from increased local intima-to-media ratio at sites of reduced glycocalyx dimension at atherogenic risk areas. These early changes in local intima-to-media ratio were without evidence of blood cell or monocyte accumulation within the extended intimal layer, indicating a minimal inflammatory response at this very early stage. In line with these observations, studies of ex vivo pig and $B 6$ mouse aortic vessel segments revealed that endothelial cells from disturbed flow regions exert priming to an inflamma- 
tory phenotype, however, without actual cytoplasm-tonuclear translocation of nuclear factor-kappa B (NF-kB) signal transduction pathway components $\mathrm{p} 65$ and IKB proteins $[11,23]$. These long-adapted endothelial cells also do not express the early NF-kB-mediated inflammatory markers intercellular adhesion molecule-1, vascular cell adhesion molecule-1 (VCAM-1), E-selectin, or P-selectin. In addition, while virtually absent in wt $B 6$ mice, substantial P-selectin and von Willebrand factor-mediated platelet adhesion was detectable to carotid endothelium in $\operatorname{apoE}^{-/-}$mice [18]. Upon this platelet to endothelium adhesion, activation of NF- $\mathrm{KB}$ and NF-KB-regulated genes such as VCAM-1 or MCP-1 followed. Introducing a LDLbodipy challenge into the murine circulation for only 15 min, we observed that significantly more LDL-bodipy accumulated within the sub-endothelial space at the lesionprone sinus region than at the common region of the carotid artery. Similar focal LDL accumulations in lesion-susceptible sites before fatty streak formation observation have been reported in cholesterol fed rabbits [2, 27] and in a porcine arterial flow setup exposed to simulated disturbed fluid flow [8]. This increased LDL-bodipy uptake within the sinus vessel wall region was accompanied by an increase in intraendothelial LDL-bodipy stained vesicle-like structures. This increase in LDL-bodipy uptake at the sinus region of $B 6$ mice does support a possible contribution for phenotypically different local endothelial cells that play an active role in LDL transport into the vascular intimal layer. Evidence for such active endothelial contributions of cells exposed to lowor slow periodicity shear forces was given in earlier studies, which revealed that formation of pinocytotic vesicles [6] and permeability to albumin $[16,28]$ were acutely sensitive to shear stress in vitro. In addition, internalization of colocalized LDL and heparan sulfate was observed recently in endothelial cells grown under static conditions while exposure to shear stress reduced uptake in time, to undetectable amounts of intracellular LDL but increased luminal presence of heparan sulfates upon $48 \mathrm{~h}$ of exposure [1]. Blocking the endocytosis process by adding the inhibitor phenyl arsine oxide, or culturing the endothelial cells at $4^{\circ} \mathrm{C}$, was able to reduce internalization of LDL and stained HS. The present study demonstrates that local vascular highpermeability sites at atheroprone arterial surfaces not only are associated with less sialic acid carrying carbohydrates as reported earlier $[9,12]$ but are also associated with a loss of HS and HA. To date, numerous studies report that specific removal of any one of the major glycocalyx carbohydrate structures impairs shear-induced NO production [7, 20, 22]. Vascular vulnerability upon perturbation of the surface glycocalyx with hyaluronidase treatment of wt $B 6$ murine vessel segments or non-specific systemic challenges in $E 3 L$ mice on an atherogenic diet was observed by the increased intimal accessibility for large fluorescent protein complexes (e.g., mouse anti-HS/goat anti-mouse IgM-AF488, HABPAF555), used for HS and HA staining, and increased intimal-LDL accumulation within the common carotid vessel wall of E3L mice (data not shown). Not only do these observations argue for involvement of the endothelial glycocalyx as a barrier for high molecular weight molecules but also strongly supports the idea that an intermingled complex 3D matrix behavior is critically dependent on all of its individual components. In addition, non-specific systemic challenges were found to compromise general protective barrier functions of the endothelial glycocalyx, which will have its earliest effect on the vulnerable atheroprone vascular sites.

In conclusion, predisposed arterial vascular regions have lower amounts of carbohydrate structures such as heparan sulfate and hyaluronan present within their luminal surface glycocalyx that results in locally reduced permeability barrier properties. In the present study, we reveal the endothelial cell glycocalyx as a complex 3D matrix, vulnerable to atherogenic risk factors, which, through preexisting differences in local architecture, results locally predisposed vulnerable arterial sites.

Acknowledgments We appreciated the support in using the confocal laser scanning microscope given by Dr. B. Nunes Cardozo.

Sources and funding This work was performed at the Department of Medical Physics, Academic Medical Center, University of Amsterdam and supported by The Netherlands Organization for Scientific Research (NWO 902-16-192) and Established Investigatorship NHF 2005 T037 to H. Vink.

Open Access This article is distributed under the terms of the Creative Commons Attribution Noncommercial License which permits any noncommercial use, distribution, and reproduction in any medium, provided the original author(s) and source are credited.

\section{References}

1. Barkefors I, Aidun CK, Egertsdotter EMU (2007) Effect of fluid shear stress on endocytosis of heparan sulfate and low-density lipoproteins. J Biomed Biotechnol 2007:8

2. Berceli SA, Warty VS, Sheppeck RA, Mandarino WA, Tanksale SK, Borovetz HS (1990) Hemodynamics and low density lipoprotein metabolism. Rates of low density lipoprotein incorporation and degradation along medial and lateral walls of the rabbit aorto-iliac bifurcation. Arteriosclerosis 10:686-694

3. Constantinescu AA, Vink H, Spaan JA (2001) Elevated capillary tube hematocrit reflects degradation of endothelial cell glycocalyx by oxidized LDL. Am J Physiol 280:H1051-H1057

4. Constantinescu AA, Vink H, Spaan JA (2003) Endothelial cell glycocalyx modulates immobilization of leukocytes at the endothelial surface. Arterioscler Thromb Vasc Biol 23:1541-1547

5. David G, Bai XM, Van der Schueren B, Cassiman JJ, Van den Berghe H (1992) Developmental changes in heparan sulfate expression: in situ detection with mAbs. J Cell Biol 119:961-975 
6. Davies PF, Dewey CF, Bussolari SR, Gordon EJ, Gimbrone MA (1984) Influence of hemodynamic forces on vascular endothelial function. In vitro studies of shear stress and pinocytosis in bovine aortic cells. J Clin Invest 73:1121-1129

7. Florian JA, Kosky JR, Ainslie K, Pang Z, Dull RO, Tarbell JM (2003) Heparan sulfate proteoglycan is a mechanosensor on endothelial cells. Circ Res 93:e136-e142

8. Fry DL (2002) Arterial intimal-medial permeability and coevolving structural responses to defined shear-stress exposures. Am J Physiol 283:H2341-H2355

9. Gorog P, Born GV (1983) Uneven distribution of sialic acids on the luminal surface of aortic endothelium. Br J Exp Pathol 64:418-424

10. Gouverneur M, Spaan JA, Pannekoek H, Fontijn RD, Vink H (2006) Fluid shear stress stimulates incorporation of hyaluronan into endothelial cell glycocalyx. Am J Physiol 290:H458-H452

11. Hajra L, Evans AI, Chen M, Hyduk SJ, Collins T, Cybulsky MI (2000) The NF-kappa B signal transduction pathway in aortic endothelial cells is primed for activation in regions predisposed to atherosclerotic lesion formation. Proc Natl Acad Sci USA 97:9052-9057

12. Haldenby KA, Chappell DC, Winlove CP, Parker KH, Firth JA (1994) Focal and regional variations in the composition of the glycocalyx of large vessel endothelium. J Vasc Res 31:2-9

13. Hem A, Smith AJ, Solberg P (1998) Saphenous vein puncture for blood sampling of the mouse, rat, hamster, gerbil, guinea pig, ferret and mink. Lab Anim 32:364-368

14. Henry CB, Duling BR (1999) Permeation of the luminal capillary glycocalyx is determined by hyaluronan. Am J Physiol 277: H508-H514

15. Jawien J, Nastalek P, Korbut R (2004) Mouse models of experimental atherosclerosis. J Physiol Pharmacol 55:503-517

16. Jo H, Dull RO, Hollis TM, Tarbell JM (1991) Endothelial albumin permeability is shear dependent, time dependent, and reversible. Am J Physiol 260:H1992-H1996

17. Liepsch D (2002) An introduction to biofluid mechanics-basic models and applications. J Biomech 35:415-435

18. Massberg S, Brand K, Gruner S, Page S, Muller E, Muller I, Bergmeier W, Richter T, Lorenz M, Konrad I, Nieswandt B, Gawaz M (2002) A critical role of platelet adhesion in the initiation of atherosclerotic lesion formation. J Exp Med 196:887-896

19. Megens RT, Reitsma S, Schiffers PH, Hilgers RH, De Mey JG, Slaaf DW, oude Egbrink MG, van Zandvoort MA (2007) Twophoton microscopy of vital murine elastic and muscular arteries. Combined structural and functional imaging with subcellular resolution. J Vasc Res 44:87-98

20. Mochizuki S, Vink H, Hiramatsu O, Kajita T, Shigeto F, Spaan JA, Kajiya F (2003) Role of hyaluronic acid glycosaminoglycans in shear-induced endothelium-derived nitric oxide release. Am J Physiol 285:H722-H726

21. Mulivor AW, Lipowsky HH (2004) Inflammation- and ischemiainduced shedding of venular glycocalyx. Am J Physiol 286: H1672-H1680
22. Pahakis MY, Kosky JR, Dull RO, Tarbell JM (2007) The role of endothelial glycocalyx components in mechanotransduction of fluid shear stress. Biochem Biophys Res Commun 355: 228-233

23. Passerini AG, Polacek DC, Shi C, Francesco NM, Manduchi E, Grant GR, Pritchard WF, Powell S, Chang GY, Stoeckert CJ, Davies PF (2004) Coexisting proinflammatory and antioxidative endothelial transcription profiles in a disturbed flow region of the adult porcine aorta. Proc Natl Acad Sci USA 101:24822487

24. Pries AR, Secomb TW, Gaehtgens P (2000) The endothelial surface layer. Pflugers Arch 440:653-666

25. Reitsma S, Slaaf DW, Vink H, van Zandvoort MA, Oude Egbrink MG (2007) The endothelial glycocalyx: composition, functions, and visualization. Pflugers Arch 454:345-359

26. Rutledge JC, Woo MM, Rezai AA, Curtiss LK, Goldberg IJ (1997) Lipoprotein lipase increases lipoprotein binding to the artery wall and increases endothelial layer permeability by formation of lipolysis products. Circ Res 80:819-828

27. Schwenke DC, Carew TE (1989) Initiation of atherosclerotic lesions in cholesterol-fed rabbits. II. Selective retention of LDL vs. selective increases in LDL permeability in susceptible sites of arteries. Arteriosclerosis 9:908-918

28. Ueda A, Shimomura M, Ikeda M, Yamaguchi R, Tanishita K (2004) Effect of glycocalyx on shear-dependent albumin uptake in endothelial cells. Am J Physiol 287:H2287-H2294

29. van den Berg BM, Spaan JA, Rolf TM, Vink H (2006) Atherogenic region and diet diminish glycocalyx dimension and increase intima-to-media ratios at murine carotid artery bifurcation. Am J Physiol 290:H915-H920

30. van den Berg BM, Vink H, Spaan JA (2003) The endothelial glycocalyx protects against myocardial edema. Circ Res 92:592594

31. van Haaren PM, VanBavel E, Vink H, Spaan JA (2003) Localization of the permeability barrier to solutes in isolated arteries by confocal microscopy. Am J Physiol 285:H2848$\mathrm{H} 2856$

32. van Vlijmen BJ, van den Maagdenberg AM, Gijbels MJ, van der Boom H, HogenEsch H, Frants RR, Hofker MH, Havekes LM (1994) Diet-induced hyperlipoproteinemia and atherosclerosis in apolipoprotein E3-Leiden transgenic mice. J Clin Invest 93:14031410

33. Vink H, Constantinescu AA, Spaan JA (2000) Oxidized lipoproteins degrade the endothelial surface layer: implications for platelet-endothelial cell adhesion. Circulation 101:15001502

34. Vink H, Duling BR (1996) Identification of distinct luminal domains for macromolecules, erythrocytes, and leukocytes within mammalian capillaries. Circ Res 79:581-589

35. Weinbaum S, Zhang X, Han Y, Vink H, Cowin SC (2003) Mechanotransduction and flow across the endothelial glycocalyx. Proc Natl Acad Sci USA 100:7988-7995 